\title{
Efficacy and Safety of Neem Seed Extract Compared with Clotrimazole in Tinea Corporis/ Cruris: A Randomized Controlled Trial
}

\author{
Poudel I', Tianco EAV ${ }^{2}$, Villafuerte LL $^{2}$ \\ ${ }^{1}$ Consultant dermatologist, Kathmandu Clinic of Cosmetic Surgery, Kathmandu, Nepal; ${ }^{2}$ Consultant dermatologist, \\ Department of Dermatology, Jose R. Reyes Memorial Medical Center, Metro Manila, Philippines
}

\begin{abstract}
Introduction: Tinea corporis and tinea cruris are common superficial fungal infections. Neem (Azadirachta indica) seed extract has shown antifungal properties in vitro, but no clinical studies have been done for superficial dermatophytoses. This study compared the efficacy and safety of $5 \%$ neem seed extract in cream base with $1 \%$ clotrimazole cream when used twice daily for four weeks, in the treatment of localized tinea corporis and/or tinea cruris.

Materials and Methods: This is a randomized, double blind, clinical trial. Patients with localized tinea corporis and/ or tinea cruris were evaluated at baseline, week 1, week 2 and week 4 . Clinical, mycological and effective cure rates of both treatment groups were determined. The patients' post treatment overall satisfaction scores and the incidence of adverse effects were also documented.

Results: Sixty patients were recruited, and 30 patients were randomized to each treatment arm. There were no significant differences in post treatment scores ( $p$ value $=0.221$ ). Effective cure, defined as the combination of marked clinical improvement and mycological cure, was seen in 20/30 (66.67\%) in the neem seed extract group and 24/30 $(80 \%)$ in the clotrimazole group (relative risk $=1.67,95 \%$ confidence interval $=0.69-4.0$ ). Post treatment overall satisfaction scores were comparable ( $p$ value $=0.333$ ). Two patients experienced adverse effects in the neem seed extract group, while there were no adverse effects in the clotrimazole group.

Conclusion: Efficacy and safety of $5 \%$ neem seed extract in cream base is comparable to $1 \%$ clotrimazole cream for the treatment of localized tinea corporis and/or tinea cruris.
\end{abstract}

Key words: Azadirachta; clotrimazole; ergosterol; potassium hydroxide; seed; tinea

\section{Introduction}

$\mathrm{T}$ inea cruris and tinea corporis are common infections caused by the dermatophytes like Trichophyton tonsurans, Trichophyton rubrum and Microsporum species. These diseases are common, with an estimated prevalence of $20 \%{ }^{1-3}$ Clinically, superficial dermatophytoses are characterized by annular, scaly lesions with central clearing. While tinea cruris presents at the groin, tinea corporis may affect any other part of the body. ${ }^{4}$ The diagnosis of superficial dermpatophytosis can be done by clinical examination, potassium hydroxide examination and fungal cultures. ${ }^{5,6}$

Address of Correspondence:

Dr. Isha Poudel

Consultant dermatologist

Kathmandu Clinic of Cosmetic Surgery, Kathmandu, Nepal.

E-mail:dr.ishapoudel@gmail.com
Treatment of tinea corporis and tinea cruris varies according to the areas involved. For localized infection, topical therapy is recommended. Systemic therapy may be indicated for extensive skin infection, immunosuppression, resistance to topical antifungal

Submitted: $11^{\text {th }}$ October 2017

Accepted: 24 ${ }^{\text {th }}$ December 2017

Published: $21^{\text {st }}$ March 2018

How to cite this article

Poudel I, Tianco EAV, Villafuerte LL. Efficacy and safety of neem seed extract compared with clotrimazole in tinea corporis/ cruris: A randomized controlled trial. Nepal Journal of Dermatology Venereology and Leprology. 2018;16(1):24-9. doi: http://dx.doi.org/10.3126/njdvl.v16i1.19400

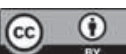

Licensed under CC BY 4.0 International License which permits use, distribution and reproduction in any medium, provided the original work is properly cited. 
therapy, and comorbidities of tinea capitis or tinea unguium. $^{7}$

Clotrimazole is widely used for the treatment of superficial dermatophytosis. It exerts its fungicidal action by inhibiting lanosterol 14-demethylase, which is important for the biosynthesis of ergosterol, a component of the fungal cell membrane. ${ }^{8-9}$

Neem (Azadirachta indica) belongs to family milliaceae (mahogany), and has been studied for various therapeutic properties including anti-bacterial, antifungal and wound healing effects. ${ }^{10}$ Sulfur-containing compounds (cyclic trisulfide and tetrasulfide), gedunin and nimbidin are components of neem shown to have antifungal properties in vitro. ${ }^{11}$ The mechanism of action is not well understood, but it is postulated that neem seed extracts may inhibit proteases which are needed in fungal physiology and development. ${ }^{12}$

To the best of our knowledge, this is the first clinical study comparing neem seed extract with an azole in the treatment of tinea corporis and/or tinea cruris.

\section{Objectives}

\section{General Objective:}

To compare the efficacy and safety of $5 \%$ neem seed extract in cream base with clotrimazole $1 \%$ cream when used twice daily for four weeks, in the treatment of tinea corporis and/or tinea cruris.

\section{Specific Objectives:}

1. To compare the post treatment clinical severity scores of both groups.

2. To compare the proportions of patients with marked clinical response after 4 weeks of treatment in both groups.

3. To compare the proportions of patients with mycological cure rates after 4 weeks of treatment in both groups.

4. To compare the proportions of patients with effective cure (marked clinical response and mycological cure) after 4 weeks of treatment in both groups.

5. To compare the patients' overall satisfaction scores at the end of treatment.

6. To compare the incidence of adverse effects in both treatment groups.

\section{Materialsand Methods}

\section{Study design}

This is a randomized, double blind, controlled trial comparing the efficacy and safety of $5 \%$ neem seed extract cream and clotrimazole $1 \%$ cream when applied twice daily for the treatment of tinea corporis and/or tinea cruris.

\section{Patient population}

New patients of the Dermatology Outpatient Department of Jose R. Reyes Memorial Medical Center, aged 18 to 65 years old, clinically diagnosed with tinea corporis and/or tinea cruris and confirmed with positive potassium hydroxide $(\mathrm{KOH})$ smears, were included. Patients were recruited from June to December 2014.

\section{Exclusion criteria}

a. Pregnant or breastfeeding women

b. Systemic disease and immunodeficiency

c. Generalized dermatophytosis needing systemic medication

d. Use of topical or oral antifungal treatment within 2 weeks prior to study commencement

e. Known allergies to neem

A certificate of approval from the Institutional Review Board of Jose R. Reyes Memorial Medical Center was obtained before the clinical trial was initiated. The study was performed in accordance with the Declaration of Helsinki and Good Clinical Practice Guidelines. Informed consent from the patients was likewise secured prior to treatment, after each subject was briefed regarding the nature of the study.

\section{Randomization, treatment allocation, and blinding}

The study statistician generated a list of random numbers using the table of random numbers. An assigned resident, who was blinded to the codes, allocated the treatments randomly using the list and dispensed the packaged jars accordingly. The codes were not disclosed to the investigators until the end of the study.

\section{Materials}

A previous in vitro study by Natarajan et al ${ }^{12}$ determined that the minimum inhibition concentration of neem seed extract against dermatophytes was $15 \mu \mathrm{g} /$ $\mathrm{ml}$. Based on this, a concentration of $5 \%$ neem seed extract was determined for this study. The neem seed extract was compounded in cream base by a registered industrial pharmacist from the University of the Philippines, Manila. Clotrimazole 1\% cream was obtained from a local pharmacy (Dermskin, Philippines). The two study creams were similar in appearance and were packed in identical jars and were coded A or B by the same industrial pharmacist. 


\section{Intervention}

The patients in both groups were instructed to apply their assigned cream on affected areas twice daily for four weeks. The selection of a four-week treatment period was based on standard therapy for superficial fungal infections with most currently available topical antifungals. ${ }^{14}$ The patients were also instructed not to apply any other topical, or take any oral medications.

\section{Clinical assessment}

The patients were evaluated at baseline, and at 1, 2, and 4 weeks by the primary investigator. The primary endpoints of the study were the proportion of patients who demonstrated marked clinical response, mycological cure and effective cure. Secondary endpoints included the clinical severity scores throughout treatment, patients' overall satisfaction scores post-treatment and the incidence of adverse events during the study.

Clinical severity scores were determined through an evaluation of scaling, erythema, burning, and itching. These were assessed using a four-point scale of 0 to 3 ( 0 = absent, 1 = mild, 2 = moderate, 3 = severe) . The scores for each parameter were added to give the total clinical score. A marked clinical response was considered to be a reduction of $\geq 2$ in the clinical score or a final value of zero. All clinical evaluations were done by the same blinded evaluator. Potassium hydroxide examinations were done by the same medical technologist for all patients. A mycological cure was defined as a negative $\mathrm{KOH}$ smear. Effective cure was defined to be the occurrence of both a marked clinical response and a mycological cure. Clinical evaluation was done at baseline, week 1 , week 2 and week 4 of treatment, while $\mathrm{KOH}$ examinations were done at baseline, week 2 and week 4 . Monitoring of adverse events and digital photography were also done during every visit.

Overall satisfaction scores were obtained post treatment by asking each patient to assess his or her overall satisfaction using a four-point scale of 0 to 3 ( 0 = worse, 1 = the same, 2 = somewhat improved, 3 $=$ markedly improved).

\section{Stopping guidelines}

The study was stopped in patients who experienced burning, erythema, or pain on application. Appropriate rescue treatment and monitoring were delivered. These patients were considered as withdrawals from the study. Those who did not comply with the treatment regimen, or those who used other topical medications, were also withdrawn from the study.
Dropouts were defined as those who did not follow up within two weeks and whose outcome was unknown by the end of the study period.

\section{Sample size}

Based on the 2013 census of the Jose R. Reyes Memorial Medical Center Dermatology Outpatient Department, there were 386 cases of tinea corporis and 290 cases of tinea cruris seen out of a total of 30,328 patients. Statistical computations indicated a minimum of 60 patients to achieve a $95 \%$ level of confidence, precision of $5 \%$, with allowance for a $20 \%$ dropout, power of $80 \%, 0.05$ significance level and equal number of cases and controls.

\section{Data processing and statistical analysis}

For demographic characteristics, student's t-test was used for continuous variables and Pearson's chi-square test for categorical data. Repeated measures analysis of variance was used to compare clinical severity scores while student's t-test was used to compare post-treatment overall satisfaction scores. Treatment effects such as relative risk, risk reduction and number needed to treat were also computed. Statistical analyses were performed using STATA Version 10 (Stata Corp LP, College Station, TX, USA). An intentionto-treat analysis was used for all patients included who received at least one dose of treatment. Test results that produced $\mathrm{p}$ values of $<0.05$ were regarded as statistically significant.

\section{Results}

Of the 72 individuals who were screened, 60 met the entry criteria and were randomized to treatment (neem seed extract group, $\mathrm{n}=30$ ) and control (clotrimazole, $\mathrm{n}=30$ ) groups. Of these patients, two were withdrawn from the treatment group because of adverse effects. There were no dropouts in both groups. Because an intention-to-treat analysis was performed, all 60 patients were included in the full analysis (Figure 1).

The baseline characteristics of the study population are summarized in Table 1 . No statistically significant differences were noted between the two groups based on age, sex, affected site, and baseline clinical scores.

Both treatment groups showed decreasing clinical severity scores throughout treatment (Figure 2). By week 2 of treatment, 25/30 (83.33\%) patients in the neem seed extract group and 28/30 (93.33\%) in the clotrimazole group had marked clinical response. After 4 weeks of treatment, all the patients in both groups had marked clinical response. Post treatment clinical 
severity scores were comparable in both groups $(p$ value $=0.221$ ). There is no statistically significant difference between two groups.

In the neem seed extract group, 10/30 (33.33\%) of patients had mycological cure by week 2 and 20/30 $(66.67 \%)$ by week 4 . In the clotrimazole group, mycological cure was achieved in 13/30 (43.33\%) of patients by week 2 and 24/30 (80\%) by week 4 (Table 2).

By the end of the treatment, $20 / 30(66.67 \%)$ in the neem seed extract group and $24 / 30$ (80\%) in the clotrimazole group had effective cure of their disease
Relative risk $(R R)=1.67,95 \%$ confidence interval $(\mathrm{Cl})=0.69-4.0)$. Relative risk reduction (RRR) for failed outcomes (those who did not achieve effective cure) was $67 \%(\mathrm{RRR}=0.67,95 \% \mathrm{Cl}=0.31-3.0)$. The number needed to treat revealed that 8 patients were required to be treated with neem seed extract cream to demonstrate effective cure. (Table 3)

Post treatment overall satisfaction scores were comparable in both groups ( $p$ value $=0.333$ ) (Table 4). Two patients experienced adverse effects in the neem seed extract group, while there were no adverse effects documented in the clotrimazole group.

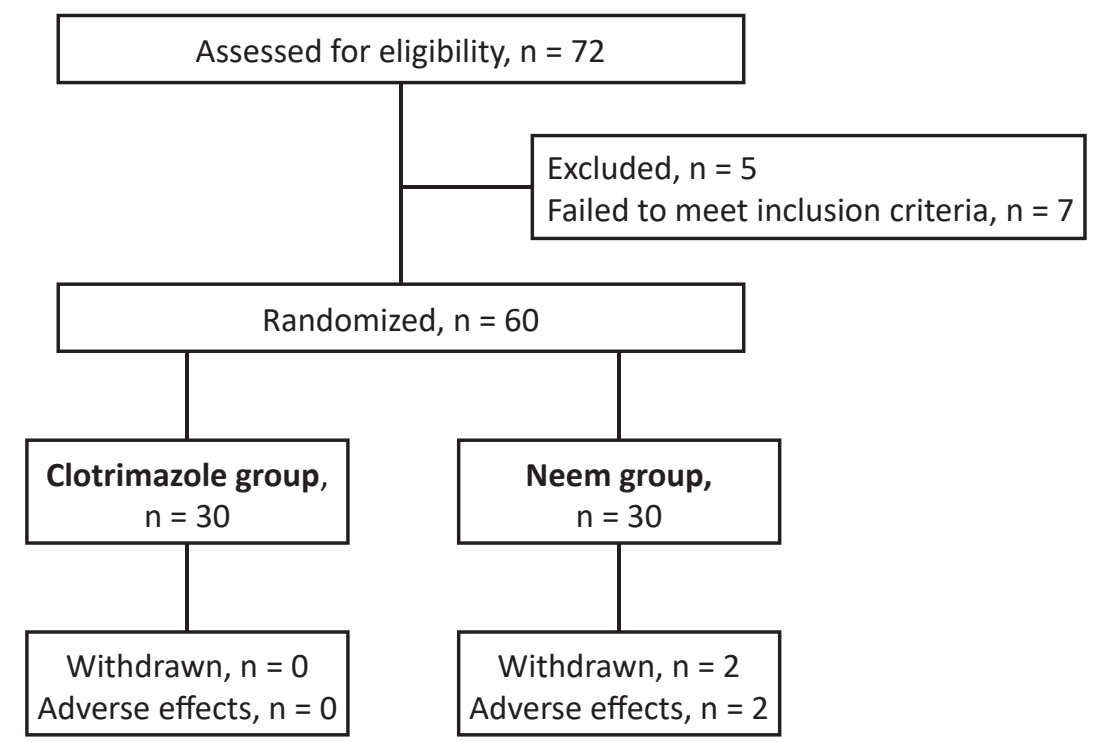

Figure 1: Trial profile showing the patient population.

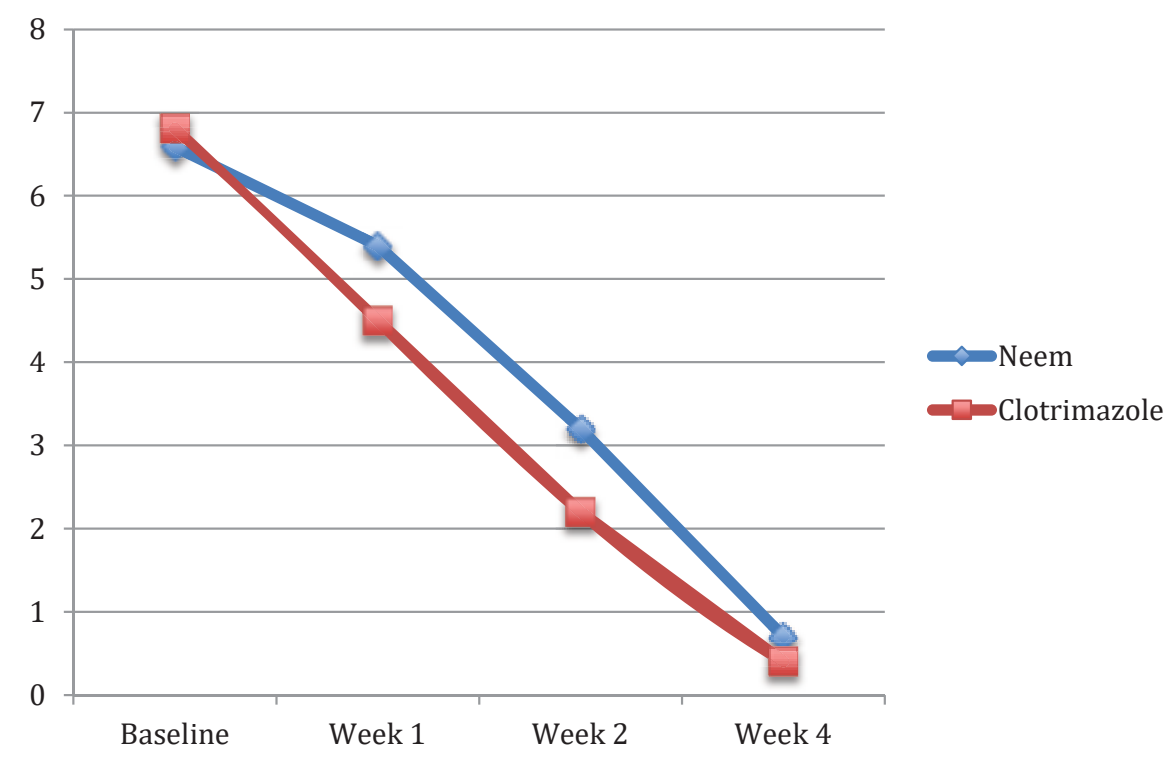

Figure 2: Clinical scores of both groups throughout the treatment. 
Table 1: Demographic characteristics of the study population.

\begin{tabular}{|l|c|c|c|}
\hline Characteristic & Clotrimazole group, $\mathbf{n}=\mathbf{3 0}$ & Neem seed extract group, $\mathbf{n}=\mathbf{3 0}$ & $\mathbf{p}$ value \\
\hline Age, years, mean \pm SD & $34.59 \pm 11.66$ & $32.73 \pm 15.28$ & 0.772 \\
\hline Sex, male/female & $11 / 19$ & $13 / 15$ & 0.091 \\
\hline Site, groin/trunk & $9 / 21$ & $9 / 19$ & 0.084 \\
\hline Erythema score, mean & 2.11 & 2.07 & 0.23 \\
\hline Scaling score, mean & 2.22 & 2.21 & 0.16 \\
\hline Pruritus score, mean & 2.52 & 2.31 & 0.83 \\
\hline Total clinical score, mean & 6.81 & 6.59 & 0.066 \\
\hline
\end{tabular}

Note: $\mathrm{SD}=$ standard deviation.

Table 2: Number of patients showing marked clinical response, mycological and effective cures.

\begin{tabular}{|l|c|c|c|c|c|c|}
\hline \multirow{2}{*}{} & \multicolumn{2}{|c|}{ Neem seed extract group, $\mathbf{n = 3 0}$} & \multicolumn{3}{c|}{ Clotrimazole group, $\mathbf{n = 3 0}$} \\
\cline { 2 - 7 } & Week 1 & Week 2 & Week 4 & Week 1 & Week 2 & Week 4 \\
\hline Marked clinical response, $\mathrm{n}(\%)$ & $18(60)$ & $25(83.33)$ & $28(93.33)$ & $26(86.67)$ & $28(93.33)$ & $30(100)$ \\
\hline Mycological cure, $\mathrm{n}(\%)$ & $0(0)$ & $10(33.33)$ & $20(66.67)$ & $0(0)$ & $13(43.33)$ & $24(80)$ \\
\hline Effective cure, $\mathrm{n}(\%)$ & $0(0)$ & $0(0)$ & $20(66.67)$ & $0(0)$ & $0(0)$ & $24(80)$ \\
\hline
\end{tabular}

Table 3: Table showing relative risk calculation

\begin{tabular}{|l|c|c|c|}
\hline & $\begin{array}{c}\text { Number of patients who did not } \\
\text { achieve effective cure }\end{array}$ & $\begin{array}{c}\text { Number of patients who achieved } \\
\text { effective cure }\end{array}$ & Total \\
\hline Neem group & 10 & 20 & 30 \\
\hline Clotrimazole group & 6 & 24 & 30 \\
\hline & 16 & 44 & 60 \\
\hline
\end{tabular}

Table 4: Overall satisfaction scores at the end of the treatment.

\begin{tabular}{|l|c|c|}
\hline & Marked improvement & Partial improvement \\
\hline Neem seed extract group, $\mathrm{n}(\%)$ & $19(68 \%)$ & $9(32 \%)$ \\
\hline Clotrimazole group, $\mathrm{n}(\%)$ & $22(73 \%)$ & $8(27 \%)$ \\
\hline
\end{tabular}

\section{Disaussion}

Both neem seed and leaf extracts have demonstrated antifungal effects, but the former has a lower minimum inhibitory concentration and is more readily available. ${ }^{13}$ Neem seed extracts have also been used for scabies, ${ }^{14}$ pediculosis capitis, ${ }^{15}$ and acne with minimal to no side effects. A study published in 2015, compared the efficacy of neem seed oil, terbinafine cream and a combination of both in treatment of dermatophytosis. It was concluded that neem seed oil is equally effective as terbinafine cream in the treatment of dermatophytosis. ${ }^{16}$

In our study, both the neem seed extract and clotrimazole groups significantly improved the clinical symptoms of the patients. The improvement with the use of neem seed extract may be attributed to its effect on fungal proteases, which are considered as virulence factors because they are needed by fungi for adherence and penetration. ${ }^{9}$ In addition, proteases may also induce inflammatory responses by altering the permeability of the epithelial barrier and by induction of pro-inflammatory cytokines through proteaseactivated receptors. These enzymes may further contribute to inflammation through interactions with the kinin system as well as the coagulation and fibrinolytic cascades. Their effect on the host protease-antiprotease balance results from activation of endogenous proteases and degradation of protease inhibitors. ${ }^{17}$ Therefore, the clinical improvement with the use of neem seed extract may be explained by the prevention of microbial spread and inhibition of inflammatory mediators associated with the inhibition of dermatophyte proteases.

Although the majority of the patients in the neem seed extract group did not experience adverse effects, two patients developed irritation, erythema and pruritus on application. Possible causative components in neem include triterpenoid compounds (such as azadirachtin and nimbin), and coumarins. ${ }^{18}$ Future studies may focus on different concentrations of neem seed extract to determine if a lower concentration may have fewer side effects and still maintain efficacy. Also, a comparison with other existing topical antifungals may 
also be conducted to further delineate the efficacy and safety of this cheaper alternative.

\section{Condusion}

Efficacy and safety of $5 \%$ neem seed extract in cream base is comparable to $1 \%$ clotrimazole cream in the

\section{References}

1. Verma S, Heffernan MP. Superficial fungal infection: Dermatophytosis, Onychomycosis, Tinea nigra, Piedra. In: Wolff K, Goldsmith L, Katz S, Gilchrest B, Paller AS, Leffell D. (eds.) Fitzpatrick's Dermatology in General Medicine (Vol 2), $7^{\text {th }}$ ed. New York: The Mc Graw-Hill; 2008. p.1814-21.

2. Carod JF, Ratsitorahina M, Raherimandimby $\mathrm{H}$, Vitrat VH, Andrianaja VR, Contet-Andonneau $\mathrm{N}$. Outbreak of Tinea capitis and corporis in a primary school in Antananarivo, Madagascar. J Infect Dev Ctries. 2011;5(10):732-6. https://doi. org/10.3855/jidc.1944

3. Silva-Tavares $\mathrm{H}$, Alchorne MM, Fischman $\mathrm{O}$. Tinea cruris epidemiology. Mycopathologia 2001;149(3):147-9. https://doi. org/10.1023/A:1007288602016

4. Gorani A, Sciera and Oriani A. Widespread tinea corporis tinea corporis due to Trichophyton rubrum. Mycoses. 2002;45(5-6): 195-7. https:// doi.org/10.1046/j.1439-0507.2002.00759.x

5. Weinstein A, Berman B. Topical treatment of common superficial tinea infections, Am Fam Physician. 2002;65:2095-103.

6. Levitt JO, Levitt BH, Akhavan A, Yanovsky H. The sensitivity and specificity of potassium hydroxide smear and fungal culture relative to clinical assessment in the evaluation of tinea pedis: $A$ pooled analysis. Dermatol Res Pract. 2010;2010:18. https://doi.org/10.1155/2010/764843

7. Havlickova B and Friedrich M. The advantages of topical combination therapy in the treatment of inflammatory dermatomycoses. Mycoses. 2008;51:16-26. https://doi.org/10.1111/j.14390507.2008.01615.x

8. Banerjee A, Ghosh AK, Basak S, Das KD, Gangopadhyay DN. Comparative evaluation of effectivity and safety of topical amorolfine and clotrimazole in treatment of tinea corporis. Indian J Dermatol. 2011;56:657-62. https://doi. org/10.4103/0019-5154.91823

9. Ramam M, Prasad HR, Manchanda $Y$, Khaitan $B K$, Banerjee U, Mukhopadhyaya A, et al. Randomized treatment of localized tinea corporis and/or tinea cruris when applied twice daily for four weeks.

Acknowledgement: The authors thank Dr. Mara Therese P. Evangelista for her helpful comments.

Financial disclosure: None.

Conflicts of interest to disclosure: None declared.

controlled trial of topical butenafine in tinea cruris and tinea corporis. Indian J Dermatol Venerol Leprol. 2003;69:154-8.

10. Brahmachari G. Neem- an omnipotent plantretrospection. Chembiochem. 2004;5:408-21. https://doi.org/10.1002/cbic.200300749

11. Biswas K, Chattopadhyay I, Banerjee RK, Bandopadhyay U. Biological activities and medicinal properties of Neem (Azadirachta indica). Current Science. 2002;82(11):1336-45

12. Natarajan V, Venugopal PV, Menon T. Effect of Azadirachta indicia on growth pattern of dermatophytes. Indian J Med Microbiol. 2003;21:98-101.

13. Alves PD, Brandao MGL, Nunan EA, ViannaSores CD. Chromatographic evaluation and antimicrobial activity of Neem (Azadirachta indica A. Juss., Meliaceae) leaves hydroalcoholic extracts. Brazilian Journal of Pharmacognosy 2009;19:510-5. https://doi.org/10.1590/S0102695X2009000400001

14. Charles V, Charles SX. The use and efficacy of Azadirachta indica ADR ('Neem') and Curcuma longa ('Turmeric') in scabies. A pilot study. Trop Geogr Med.1992;44:178-81.

15. Abdel-Ghaffar F, Semmler M. Efficacy of neem seed extract shampoo on head lice of naturally infected humans in Egypt. Parasitol Res. 2007;100(2):329-32. https://doi.org/10.1007/ s00436-006-0264-2

16. Bala SS, Chincholkar A, Wagh R, Mutalik M, Siddiqui W, Gupta M. A comparative study of efficacy of neem seed oil, terbinafine cream and a combination of both terbinafine cream and neem seed oil applied topically in the treatment of clinical dermatophytosis. World Journal of Pharmacy and Pharmaceutical sciences 2015;4(10):1263-74.

17. Yike I. Fungal proteases and their pathophysiological effects. Mycopathologia. 2011;171:299-323. https://doi.org/10.1007/ s11046-010-9386-2

18. Greenblatt DT, Banerjee P, White JM. Allergic contact dermatitis caused by neem oil. Contact Dermatitis 2012;67:242-3.. 